\title{
INFLUÊNCIA DE ADERÊNCIAS PERITONEAIS E FIO CIRÚRGICO NA TENSÃO DE RUPTURA DA PAREDE ABDOMINAL EM RATOS
}

\author{
INFLUENCE OF PERITONEALADHESIONS AND SUTURE LINE IN THE TENSILE \\ STRENGTH OF SURGICAL WOUND IN RATS
}

\author{
Roberto Martins Gonçalves ${ }^{1}$ \\ Carlos Roberto Messeder Esquerdo ${ }^{1}$ \\ Andy Petroianu, TCBC-MG \\ Alfredo José Afonso Barbosa ${ }^{3}$
}

\begin{abstract}
RESUMO: O resultado de operações na cavidade abdominal pode ser influenciado por aderências. Existem muitos conceitos ainda não comprovados sobre os efeitos das aderências na resistência de suturas tanto de vísceras intracavitárias quanto da parede abdominal. O presente trabalho visa a avaliar a influência das aderências peritoneais e vários tipos de fios cirúrgicos na tensão de ruptura da parede abdominal. Em 60 ratos Wistar, realizou-se laparotomia de $5 \mathrm{~cm}$ de comprimento. A parede muscular e o peritônio foram fechados em plano único, com pontos simples, usando aleatoriamente os fios de náilon monofilamentar, ácido poliglicólico, categute simples e categute cromado, todos 4-0. Os animais foram divididos em três grupos: 1- Controle; 2- Introdução de 0,3g de talco dentro da cavidade abdominal; 3- Acréscimo de carboximetilcelulose sódica (CMC) juntamente com o talco. Houve a análise dos grupos com sete e 21 dias. Avaliou-se o grau de aderências e a tensão de ruptura da ferida cirúrgica. A CMC reduziu a formação de aderências provocadas pelo talco $(\mathrm{p}<0,01)$. Houve diferença na tensão de ruptura quando comparados os grupos de sete e 21 dias $(\mathrm{p}<0,05)$. As aderências proporcionaram uma maior força tênsil à ferida $(\mathrm{p}<0,01)$. $\mathrm{O}$ tipo de fio utilizado não influenciou na tensão de ruptura a longo prazo. Portanto, as aderências aumentaram a força tênsil dos tecidos e o tipo de fio cirúrgico não influenciou nesse processo.
\end{abstract}

Unitermos: Aderência, Fio de sutura, Tensão de ruptura, Rato, Talco, Carboximetilcelulose.

\section{INTRODUÇÃO}

Durante os últimos anos, numerosos estudos têm avaliado os diversos materiais de sutura e fenômenos relacionados com a cicatrização. Em relação ao abdome, tanto em exames post-mortem como em laparotomias, encontra-se alta frequiência de aderências assintomáticas. Weibel e Majno examinaram 298 cadáveres, que foram submetidos a laparotomia prévia, nos quais se obteve um índice de $67 \%$ de aderências. Após múltiplas cirurgias sua porcentagem aumentava para $93 \%{ }^{1}$
As aderências representam a causa mais comum de obstrução intestinal nos países desenvolvidos, diferentemente da hérnia estrangulada que ainda ocupa o primeiro lugar nos países em desenvolvimento, devido a uma menor freqüência de laparotomias. ${ }^{2,3}$ A literatura registra que em vários países ocorreu uma mudança marcante no padrão etiológico das obstruções intestinais mecânicas. Nos primeiros decênios deste século, a hérnia estrangulada foi sua causa mais comum. ${ }^{4}$ Entretanto, com o tratamento cirúrgico precoce, as hérnias deixaram de ser representativas como agentes etiológicos dos íleos mecânicos nos

1. Médico Residente. Bolsista do CNPq.

2. Professor Titular do Departamento de Cirurgia da Faculdade de Medicina da UFMG, Docente Livre da Escola Paulista de Medicina - UNIFESP, Docente Livre da Faculdade de Medicina de Ribeirão Preto - USP, Pesquisador IA do CNPq.

3. Professor Titular do Departamento de Anatomia Patológica da Faculdade de Medicina da UFMG.

Recebido em 5/8/99

Aceito para publicação em 10/12/99

Trabalho realizado no Departamento de Cirurgia da Faculdade de Medicina da Universidade Federal de Minas Gerais UFMG. 
países mais avançados. Por outro lado, nas regiões menos desenvolvidas sob aspectos cultural e sanitário, as hérnias continuaram predominando. $\mathrm{O}$ volvo é também uma causa maior de obstrução intestinal, principalmente em nosso país, devido ao megacólon. ${ }^{3}$

O exsudato fibrinoso, desenvolvido durante as cirurgias da cavidade abdominal, pode ser reabsorvido, sem a formação de aderências. Contudo, se houver migração de fibroblastos, a organização de fibrina se desenvolve. Um dos fatores determinantes na organização ou na reabsorção dessa fibrina é a integridade do endotélio peritoneal. Um grande número de observações clínicas e experimentais confirma que áreas cruentas ou de tecido isquêmico dentro da cavidade abdominal levam ao desenvolvimento de aderências a esses locais. Outra causa de aderência peritoneal é a contaminação da cavidade abdominal, tanto por bactérias, quanto pela presença de corpos estranhos (talco de luva, restos de fios cirúrgicos etc.). ${ }^{5,6}$ Portanto, a agressão peritoneal deve ser a mais reduzida possível.

Por outro lado, existe um consenso de que as aderências peritoneais podem desempenhar um papel protetor na preservação de tecidos lesados durante o ato cirúrgico. Experimentalmente, mostrou-se que, se as aderências forem prevenidas, um segmento de intestino privado de suprimento sangüíneo irá invariavelmente gangrenar. ${ }^{7}$ Entretanto, em presença de aderências, parece haver maior probabilidade de o intestino manter a sua vitalidade. Esse fenômeno decorre da neoformação vascular a partir das aderências e que invade o tecido isquêmico.

Se houver a intenção de prevenir aderências, isso poderá ser obtido das seguintes maneiras: 2, 8, 9, 10

- Prevenção da deposição de fibrina com o uso de anticoagulantes como o citrato sódico, heparina, dicumarol e dextran, e aprotinina como um possível agente antiplasminogênico.

- Remoção do exsudato fibrinoso por meio de lavagem peritoneal ou por métodos enzimáticos.

- Separação das superfícies serosas por meio de distensão abdominal, estímulo do peristaltismo ou uso de substâncias "oleosas".

- Inibição da proliferação fibroblástica com anti-histamínicos, corticosteróides e drogas citotóxicas.

Um método utilizado experimentalmente para prevenir a formação de aderências peritoneais é o uso intracavitário de carboximetilcelulose sódica (CMC). Essa substância cria um meio líquido no qual as vísceras "flutuam" e são isoladas umas das outras. Não existindo contato entre as serosas, ocorre a regeneração do peritônio sem a formação de aderências. ${ }^{11,12}$

Uma síntese cirúrgica segura é essencial para uma apropriada recuperação após cirurgias abdominais. Nesse tempo operatório, devem ser considerados a aproximação adequada dos tecidos, o aumento gradual de sua resistência e o tempo necessário para o fio de sutura perder sua tensão inicial. ${ }^{13,14}$ As complicações mais graves deste tipo de cirurgia são as deiscências, as hérnias incisionais e a infecção da ferida, que decorrem, em parte, das condições do paciente, do tipo de incisão, da técnica e do material usados na sutura. ${ }^{15,16}$
O uso de fios monofilamentares reduz o crescimento bacteriano e a resposta inflamatória provocada por eles, quando se compara com fios multifilamentares. Entretanto, um número maior de nós deve ser dado para anular a tendência que esses fios possuem de desfazerem os nós, podendo provocar reação local a esse acúmulo de fio, com

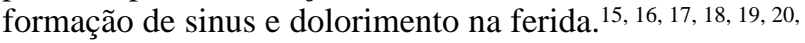
${ }^{21}$ Por outro lado, o uso de material absorvível resulta em uma maior incidência de hérnias incisionais, devido à perda de $80 \%$ da resistência em duas semanas, enquanto o tecido musculoaponeurótico requer cerca de 120 dias para completa cicatrização. ${ }^{21,23}$

A sutura contínua tem a vantagem de distribuir a tensão pela sua linha e de ser um método rápido, mas possui a desvantagem de a síntese ser feita com um único fio que, se rompe ou perde a resistência, podendo comprometê-la. A sutura múltipla é segura, mas o tempo necessário para a sua realização é maior e a tensão na ferida cirúrgica é irregular. ${ }^{24}$

A diversidade de técnicas cirúrgicas é um fator que interfere na escolha da conduta a ser tomada. O fechamento da parede abdominal sem a utilização de fios cirúrgicos na pele, sendo realizada apenas a aproximação subcutânea, tem mostrado resultados a longo prazo semelhantes aos estudos com suturas intradérmicas, com a vantagem de não necessitar da remoção da sutura. ${ }^{25,26}$

O presente trabalho tem como objetivo avaliar a influência de diversos tipos de fios cirúrgicos na resistência à ruptura da parede abdominal, após laparotomia, e o papel das aderências nesse processo.

\section{MATERIAL E MÉTODOS}

Foram utilizados 60 ratos Wistar, 36 machos e 24 fêmeas, pesando entre 250-350 gramas. Os animais foram submetidos à laparotomia paramediana medial esquerda de aproximadamente $5 \mathrm{~cm}$ de comprimento, sob anestesia com éter. A parede muscular e o peritônio foram fechados em plano único, com pontos simples, mantendo uma distância de $0,5 \mathrm{~cm}$ entre eles. A síntese, em sua metade, foi realizada aleatoriamente com um determinado fio e a outra parte com outro tipo, todos 4-0. Os fios utilizados para sutura do plano musculoaponeurótico foram náilon monofilamentar, ácido poliglicólico, categute simples e categute cromado. A pele foi suturada separadamente com pontos simples, utilizando o fio de ácido poliglicólico 4-0.

Os animais foram divididos em três grupos principais:

- Grupo 1: Controle; a cavidade abdominal aberta e em seguida suturada em dois planos;

- Grupo 2: Abertura da cavidade abdominal e introdução de $0,3 \mathrm{~g}$ de talco próximo à ferida cirúrgica e fechamento em dois planos;

- Grupo 3: Semelhante ao grupo 2, acrescentando-se ainda $10 \mathrm{ml}$ de solução de CMC a $1 \%$ dentro da cavidade, antes do fechamento do último ponto.

Cada grupo foi dividido em dois subgrupos, de acordo com os períodos pós-operatórios: análise no 7oㅡ $\operatorname{dia}(\mathrm{n}=10)$ e no $21^{\circ}$ dia $(\mathrm{n}=10)$. 
Na data prevista, os animais foram mortos com uma inalação excessiva de éter. Em cada animal foi separada a pele da parede muscular e realizada abertura da cavidade em forma de U em torno da cicatriz cirúrgica. Em seguida, as aderências à ferida cirúrgica foram classificadas, recebendo uma pontuação de acordo com a intensidade (Tabela 1).

Tabela 1

Classificação das aderências abdominais.

\begin{tabular}{c|c}
\hline Intensidade & \multicolumn{1}{c}{ Parâmetros } \\
\hline 0 & Ausência completa de aderências \\
1 & Aderência do omento maior à ferida cirúrgica \\
2 & Aderências do omento maior e do intestino \\
& delgado à ferida cirúrgica. \\
3 & Aderências múltiplas intracavitárias.
\end{tabular}

Após avaliar-se o grau de aderências, foram retirados fragmentos de $1,0 \times 2,0 \mathrm{~cm}$ em cada parte da ferida, correspondente a cada tipo de fio cirúrgico. Em seguida, cada fragmento foi à avaliação da tensão de ruptura. Os fios, quando identificados, foram cortados com tesoura delicada para que não interferissem na medida da tensão de ruptura.

Cada fragmento foi pinçado em ambas as extremidades com duas pinças de Duval. A pinça da extremidade superior foi fixada a um suporte, junto à torneira de um frasco de água. A outra pinça foi conectada a um recipiente de plástico (um copo de Becker de $2.000 \mathrm{ml}$ ) com peso conhecido. Esse recipiente foi sendo enchido com água destilada a uma velocidade de $3.000 \mathrm{ml} / \mathrm{minuto}$. O fluxo de água foi interrompido no momento de ruptura do segmento de parede abdominal. Calculou-se a força necessária para romper cada segmento, pelo peso da água somado ao do copo e ao da pinça inferior.

Em seguida, os segmentos de parede abdominal foram fixados em formol a $10 \%$, desidratados em álcool e xilol, e incluídos em parafina, a vácuo. De cada fragmento, foram seccionados cortes histológicos de $7 \mu \mathrm{m}$ de espessura, que foram fixados em duas lâminas. Uma das lâminas de cada fragmento foi corada pela hematoxilina e eosina, enquanto a outra o foi pela técnica de Picro-Sirius. ${ }^{27}$ Estas últimas preparações foram examinadas à microscopia de polarização para se avaliar a presença de fibras colágenas tipo I, II e III, tendo em vista que ela permite a identificação seletiva dessas estruturas. ${ }^{28,29}$

\section{RESULTADOS}

Não houve aderências no Grupo 1. As médias das aderências nos Grupos 2 e 3 foram, respectivamente, 2,350 $\pm 0,802$ e $1,176 \pm 0,521(\mathrm{p}<0,01)$, mostrando que a CMC reduziu a formação de aderências provocadas pelo talco (Tabela 2).
Tabela 2

Média do grau de aderências em cada grupo

\begin{tabular}{l|c|c|c}
\hline & 7 dias & 21 dias & Total \\
\hline Grupo1 & 0 & 0 & 0 \\
Grupo2 & $2,1 \pm 0,718^{* *}$ & $2,6 \pm 0,821^{* *}$ & $2,35 \pm 0,802^{*}$ \\
Grupo3 & $1,25 \pm 0,683$ & $1,11 \pm 0,323$ & $1,17 \pm 0,521^{*}$ \\
\hline
\end{tabular}

* Diferença para $p<0,01$.

** Diferença para $p<0,05$.

No grupo em que foi colocado apenas o talco dentro da cavidade abdominal, houve um aumento do grau de aderências no grupo de 21 dias $(2,600 \pm 0,821)$ quando comparado com o grupo de sete dias $(2,100 \pm 0,718)$ $(\mathrm{p}=0,046)$. Já no grupo em que foi utilizada a CMC, essa diferença não foi observada $(\mathrm{p}=0,398)$. Esse achado pode ser explicado pela ação constante do talco como um irritante peritoneal, aumentando o processo exsudativo, mas que no grupo com CMC é prejudicada pela separação das superfícies serosas com déficit da formação de fibrina entre as estruturas abdominais.

Em todos os grupos houve diferença no valor da resistência à ruptura, quando comparados os grupos de sete e 21 dias, revelando que o processo cicatricial ainda não estava completo no sétimo dia. Na comparação entre os grupos, pode-se observar diferença na resistência à ruptura da ferida cirúrgica apenas entre os grupos de 21 dias do Grupo Controle e do Grupo com talco $(\mathrm{p}<0,01)$ (Tabela 3). Esse achado mostra que as aderências abdominais influenciaram a resistência da parede abdominal. No Grupo 1, no qual não ocorreu a formação de aderências, a resistência foi significativamente menor que no Grupo 2, no qual o grau de aderências foi maior entre os três grandes grupos.

Observou-se também que, nos grupos de 21 dias, o local de ruptura no momento da avaliação da tensão foi, em $62 \%$ dos casos, nos tecidos vizinhos à ferida cirúrgica, sendo que nos grupos de sete dias a ruptura ocorreu em $82,2 \%$ dos casos no tecido em cicatrização.

Tabela 3

Médias das tensões de ruptura de cada grupo estudado

\begin{tabular}{l|c|c}
\hline \multicolumn{1}{c|}{ Grupo } & Tempo (dias) & Tensão $(\mathrm{g})$ \\
\hline 1 - Controle* & 7 & $825,0 \pm 200,2$ \\
& 21 & $1090,0 \pm 172,9^{* *}$ \\
2 - Talco* & 7 & $965,5 \pm 291,7$ \\
& 21 & $1417,0 \pm 166,8^{* *}$ \\
3 - Talco e CMC* & 7 & $771,2 \pm 401,4$ \\
& 21 & $1227,2 \pm 300,1$ \\
\hline
\end{tabular}

* Houve diferença significativa quando comparados os grupos aos 7 e 21 dias; Grupo 1 ( $p<0,01)$, Grupo 2 ( $p=0,02)$, Grupo $3(p<0,01)$.

** Diferença para $p<0,01$. 
Para comparação dos fios cirúrgicos, foi analisado o Grupo Controle. Houve diferenças em relação aos fragmentos com o fio de náilon. Neste, a resistência foi menor nos grupos aos sete dias. Entretanto, nos grupos aos 21 dias, esse material obteve um resultado semelhante aos demais fios. Não houve diferença estatisticamente significante entre os outros fios (Tabela 4).

Tabela 4

Média das resistência à ruptura $(\mathrm{g})$ nos grupos dos tipos de fios utilizados.

\begin{tabular}{l|ll}
\hline & \multicolumn{1}{|c|}{7 dias } & \multicolumn{1}{c}{21 dias } \\
\hline Ácido poliglicólico & $930,0 \pm 197,82$ & $1175,0 \pm 28,86$ \\
Náilon monofilamentar & $656,0 \pm 143,28^{*}$ & $1062,0 \pm 154,01$ \\
Categute simples & $882,85 \pm 164,59$ & $1067,14 \pm 261,13$ \\
Categute cromado & $830,0 \pm 251,26$ & $1080,0 \pm 90,55$ \\
\hline
\end{tabular}

* Houve diferença quando comparado com os fios de ácido poliglicólico $(p=0,03)$ e categute simples $(p=0,02)$.
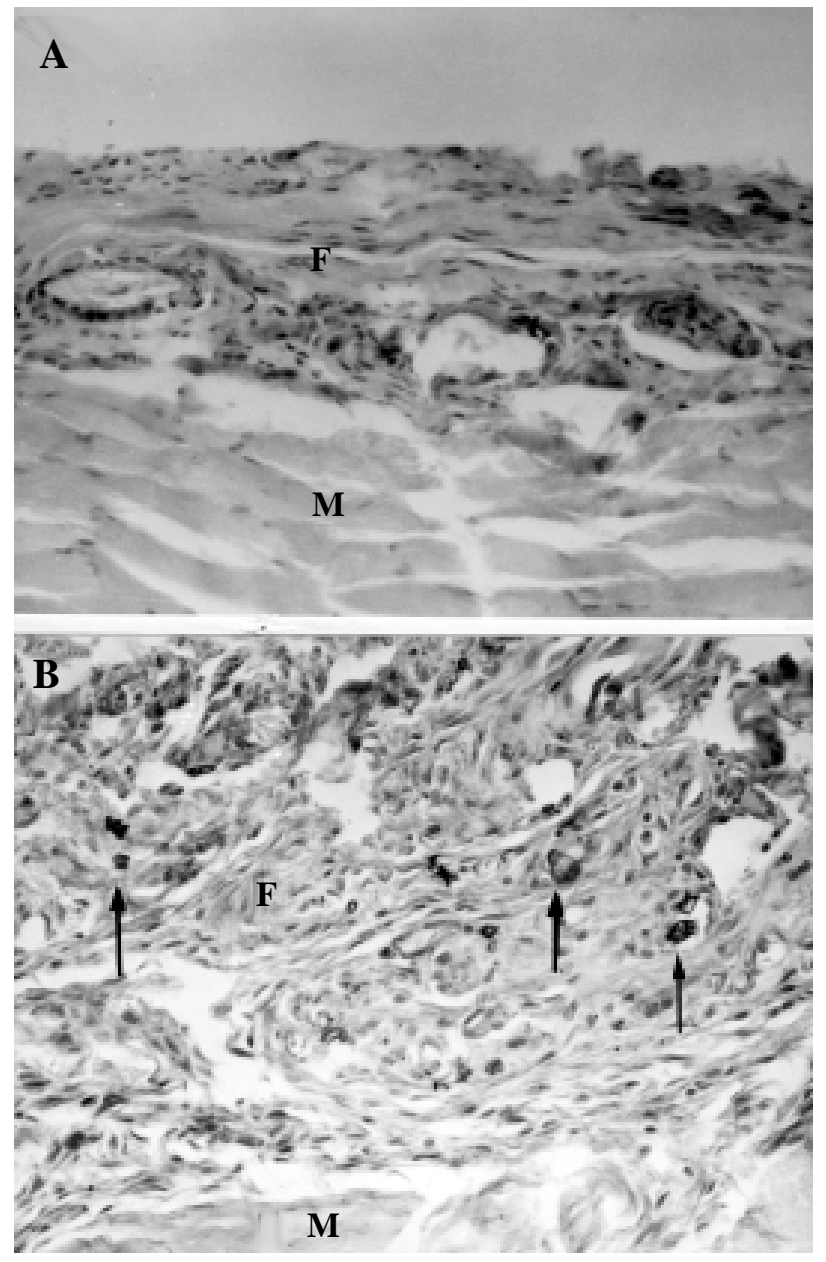

Figura 1 - Fotomicrografia da região da sutura da parede abdominal de ratos, 21 dias após a cirurgia. A-sutura realizada apenas com fio de náilon 4-0; $B$ - sutura com fio de náilon 40 , talco e carboximetilcelulose. Observa-se que em (B), o tecido fibroso encontra-se mais desenvolvido do que em (A). Setas = grânulos de talco; $F=$ tecido fibroso; $M=$ tecido muscular da parede abdominal. (A e B, hematoxilina e eosina, 200x).
A histologia do material estudado revelou maior quantidade de fibras colágenas e tecido fibroso mais desenvolvido no grupo submetido à infusão de talco junto com carboximetilcelulose. As Figuras 1 e 2 mostram os aspectos histológicos encontrados no tecido cicatricial após 21 dias da operação.

\section{DISCUSSÃO}

Em concordância com a literatura disponível, o presente trabalho, que faz parte de uma linha de pesquisa, mostrou que a CMC é capaz de impedir a formação de aderências peritoneais. $3,10,12,14,25,26,30$ A opção por realizar-se o trabalho em ambos os sexos foi porque, de acordo com a literatura, não há diferença cicatricial significativa provocada pelos hormônios sexuais. De fato, os resultados do presente trabalho confirmaram essas informações por não se encontrar diferença de resultados atribuível ao sexo dos animais em qualquer dos grupos.
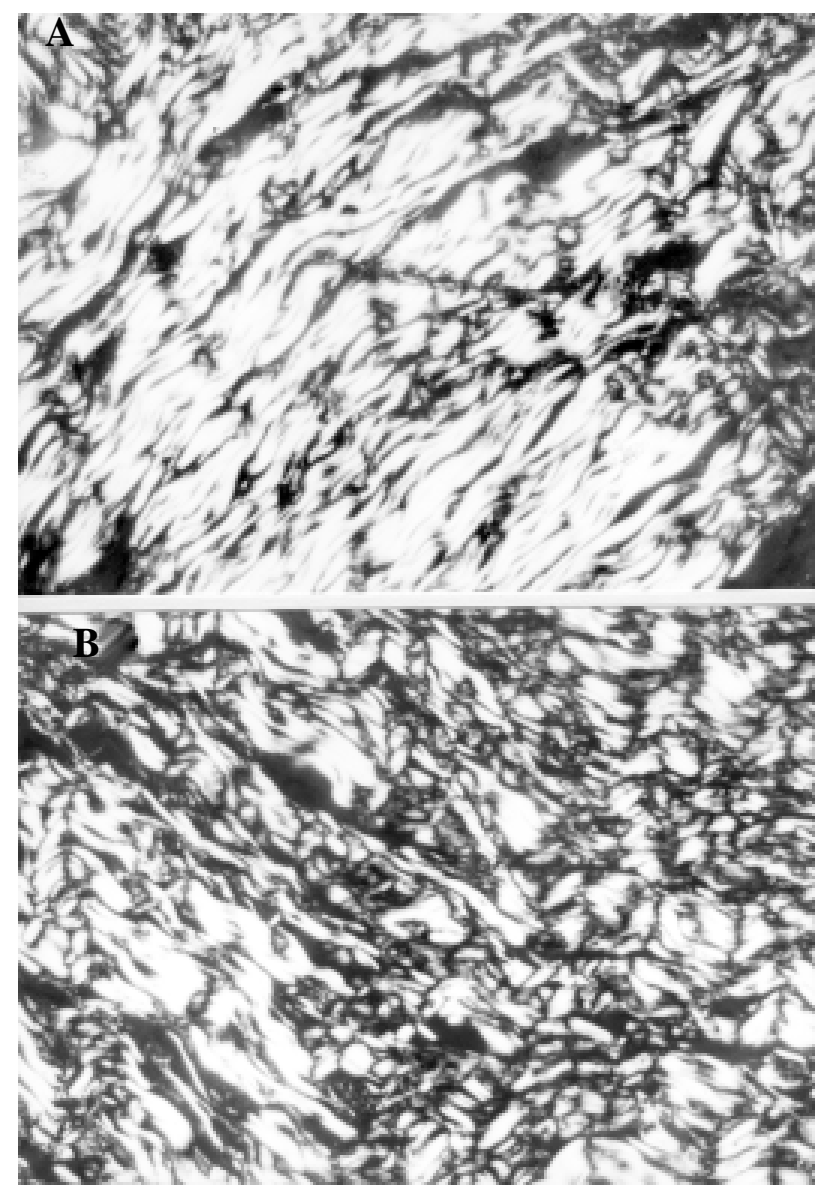

Figura 2 - Fotomicrografia de preparações histológicas, examinadas com luz polarizada, da região da sutura da parede abdominal de ratos, 21 dias após a cirurgia. A-sutura procedida apenas com fio de náilon 4-0. Predomínio de fibras colágenas tipo I, fortemente birrefringentes. Poucas fibras colágenas tipo III; B-sutura procedida com fio de náilon 4-0, talco e carboximetilcelulose. Aumento proporcional de fibras colágenas tipo I e III. Predomínio de fibras colágenas tipo I. (A e B, PicroSirius, 80x). 
A ausência de aderências no Grupo 1 pode ser explicada, pelo menos em parte, pela não manipulação das estruturas intracavitárias, diminuindo o grau de lesão tecidual. Apesar disso, a própria abertura da cavidade abdominal já seria o suficiente para que algum grau de aderência se formasse.

As aderências podem, eventualmente, provocar a obstrução intestinal, mas não se pode esquecer que a maioria das aderências é assintomática e, em muitas circunstâncias, elas exercem um papel protetor, isolando regiões comprometidas por afecções inflamatórias. Quanto ao $\mathrm{CMC}$, muitas questões ainda continuam sem resposta em relação a efeitos colaterais e dosagem mais adequada.

A menor resistência à ruptura, observada nos fragmentos no sétimo dia pós-operatório com náilon pode ser explicada pela menor reação inflamatória provocada pelos fios inabsorvíveis. Após três semanas, a resistência foi semelhante à verificada com os demais fios. De acordo com Foresman et al, a sutura exerce um importante papel na resistência musculoaponeurótica até o 42 으 dia pós-operatório. ${ }^{13}$

Parece que a escolha do fio cirúrgico a ser utilizado exerceu um efeito menor no processo de cicatrização. Portanto, a escolha da técnica cirúrgica e do material empregado deve ser baseada em fatores como as condições do paciente e o tipo de tecido suturado.

Após 21 dias, as rupturas ocorreram geralmente nos tecidos vizinhos à cicatriz. Este achado sugere que o tecido cicatricial torna-se mais resistente que o tecido vizinho.

Concluindo, as aderências intra-abdominais aumentaram a tensão das cicatrizes de parede abdominal. $\mathrm{O}$ tipo de fio não influência na resistência cicatricial, em rato após três semanas.

\begin{abstract}
The recovery of an abdominal procedure depends on many factors, including adhesions. The present study was undertaken to evaluate the influence of four types of suture lines and of adhesions on the tensile strenght of surgical wounds. Sixty Wistar rats were submitted a $5 \mathrm{~cm}$ laparotomy. The abdomen was closed in two layers with an interrupted suture, using monofilament nylon, polyglicolic acid, plain catgut and chromic catgut. The animals were dividided into three groups: 1- Control; 2- Addition of 0.3 grams of talc into abdominal cavity; 3Instillation of sodium carboxymethylcellulose (CMC) and talc into abdominal cavity. The animals were assessed on the $7^{\text {th }}$ and $21^{\text {st }}$ postoperative days. The CMC reduced adhesions $(p<0,01)$. The presence of adhesions was able to enhance the tensile strenght. The type of suture line did not influence the tensile strenght.
\end{abstract}

Key Words: Adhesion, Tensile strenght, Rat, Talc, Carboxymethylcellulose.

\section{REFERÊNCIAS}

1. Weibel MA, Majno G: Peritoneal adhesions and their relation to abdominal surgery. Am J Surg. 1973; 126: 34553.

2. Ellis H: The causes and prevention of intestinal adhesions. Br J Surg. 1982; 69: 241-243.

3. Petroianu A, Sabino LO, Neto JEO et al: Principais causas de obstrução intestinal mecânica de tratamento cirúrgico, em crianças e em adultos. Folha Médica. 1994; 109: 53-55.

4. Mc Entee G, Pender D, Mulvin D et al: Current spectrum of intestinal obstruction. Br J Surg. 1987; 74: 97680.

5. Luttwark EM, Feldman JD, Neuman Z: Effect of streptokinase-streptodornase on peritoneal talc adhesions and granulomas. Arch Surg. 1954; 68: 69-76.

6. Myllarniemi H: Foreign material in adhesion formation after abdominal surgery. Acta Chir Scand. 1967; Suppl. 377.

7. Ellis H: The aetiology of postoperative abdominal adhesions. Br J Surg. 1962; 50: 10-16.

8. Boys F: The prophylaxis of peritoneal adhesions. Surgery 1942; 11: 118-68.

9. Connolly JE, Smith JW: The prevention and treatment of intestinal adhesions. Surg Gynecol Obstet 1960; 110: 417-31.
10. Arantes VN, Okawa RY, Petroianu A et al: Efeito da metilprednisolona sobre a tensão anastomótica jejunal. Arq Gastroenterol. 1994; 31: 97-102.

11. Parra OM, Saad WA, Ferri S, Peduto L et al.: Dose-dependência da associação carboximetilcelulose-papaína na prevenção de aderências peritoneais. Arq Gastroenterol. 1991; 28: 99-102.

12. Petroianu A, Carvalho LB, Rocha KED et al: Prevention of abdominal adhesions does not interfere with jejunal anastomosis healing. J Surg Invest. 1999; 1:149-156.

13. Foresman PA, Edlich RF, Rodeheaver GT: The effect of new monofilament absorbable sutures on the healing of musculoaponeurotic incisions, gastrotomies, and colonic anastomoses. Arch Surg June 1989; 124: 70810.

14. Melo MAB, Almeida LM, Petroianu A et al: Cicatrização de anastomose colônica em ratos submetidos a diferentes preparos colônicos. Rev Bras Colo-Proct. 1996; 16: 19-22.

15. Sahlin S, Ahlberg J, Granströn L, Ljungströn KG: Monofilament versus multifilament absorbable sutures for abdominal closure. Br J Surg. 1993; 80: 322-24.

16. Wadström J, Gerdin B: Closure of the abdominal wall. Acta Chir Scand. 1990; 156: 75-82.

17. Bucknall TE: Abdominal wound closure: choice of suture. J R Soc Med. 1981; 74: 580-85. 
18. Gys T, Hubens A: A prospective comparative clinical study between monofilament absorbable and non-absorbable sutures for abdominal wall closure. Acta Chir Belg. 1989; 89: 265-70.

19. Leaper DJ: Laparotomy closure. Br J Hosp Med. 1985; 6: 317-22.

20. Poole GV: Mechanical factors in abdominal wound closure. Surgery 1985; 97: 631-9.

21. Postletwait RW, Willigen DA, Ulin AW: Human tissue reaction to sutures. Ann Surg. 1975; 181: 144-50.

22. Bucknall TE, Ellis H: Abdominal wound closure: a comparision of monofilament nylon and polyglycolic acid. Surgery 1981; 89: 672-77.

23. Wissing J, Schattenkerk ME et al: Fascia closure after midline laparotomy. Br J Surg. 1987; 74: 738-41.

24. Richards PC, Balch CM, Aldrete JS: Abdominal wound closure. Ann Surg. 1983; 197: 238-43.

25. Petroianu A: Synthesis of surgical wounds without skin sutures. Plastic and Reconstructive Surgery 1988; 82: 919-20.

26. Petroianu A: Síntese de ferida cirúrgica sem sutura da pele. Presse Méd. 1983; 2: 86-89.

27. Junqueira LCU, Cossermelli WS, Brentani RR: Differential staining of collagen type I, II and III by Sirius Red and polarization microscopy. Arch Histol Japon. 1978; 41: 267-74.

28. Constantine US, Mowry RW: The selective staining of human dermal collagen II - The use of Picrosirius red F3BA with polarization microscopy. J Invest Dermatol. 1968; 50: 419-24.
29. Junqueira LCU, Bignolas E, Brentani RR: Picrosirius staining plus polarization microscopy: a specific method for collagen detection in tissue sections. Histoch $J$. 1979; 447-55.

30. Sahin Y, Saglam A: Synergistic effects of carboxymethylcellulose and low molecular weight heparin in reducing adhesion formation in the rat uterine horn model. Acta Obstet Gynecol Scand. 1994; 73: 70-73.

\section{ENDERECOO PARA CORRESPONDÊNCIA:}

Dr. Andy Petroianu

Av. Afonso Pena, 1.626/1901

30130-005 - Belo Horizonte - MG

Fone/Fax: (031) 274-7744 